\title{
Owner-driver schemes and productivity
}

\author{
Alan Fitz-Patrick \& Frank M. Horwitz* \\ Graduate School of Business, University of Cape Town, Breakwater Campus, Private Bag. Rondebosch, 7701 South Africa
}

Received October 1998

\begin{abstract}
Owner-driver schemes are being introduced by companies wanting productivity improvements in the distribution of their products. This article examines motivating factors for owner-driver schemes and evaluates findings from interview-based research. It also examines factors relating to owner-driver schemes and productivity improvement and identifies issues concerning their design, implementation and management. Findings suggest that owner-driver schemes improve productivity and that key factors concur with a model of the motivational cycle underlying implementation of owner-driver schemes.
\end{abstract}

*Author to whom correspondence should be addressed.

\section{Introduction}

Productivity is the single most important determinant of competitiveness in a modern economy (Ryan, 1995: 12). While efficient and flexible utilisation of all resources is essential, this article concentrates on potential labour productivity improvements resulting from owner-driver schemes in the distribution industry.

Owner-driver schemes concern the creation of independent, small businesses by outsourcing the distribution function of larger enterprises. These businesses are typically run by former employees but, with maturity, some schemes look externally for their owner-drivers. A transfer of assets, namely the vehicle(s), accompanies the implementation of the scheme. They are similar to franchising: policies and procedures are standardised and controlled, allowing for operational conformity; franchisees and owner-drivers own assets of the business and make a profit from its operations; both operate under one banner and there is transfer of skills, through initial and ongoing training by the company (Leshilo, 1995: 19).

These schemes were highlighted in the South African distribution industry by South African Breweries (SAB) in 1987. Since then, several organisations have embarked on similar schemes - 'they have become increasingly popular as more South African companies restructure their operations and seek ways to widen participation in the economy' (Leshilo, 1995). Certain motivating factors are applicable where owner-driver schemes are being implemented - these factors are aligned with business strategies to improve company performance, for example, focusing on core competencies, outsourcing, and employee empowerment. In following these strategies, managers seek to lever entrepreneurial endeavour into increased company profits. Where this results in successful small businesses there is a broader benefit in terms of govemment policy to promote small business. Criticism of these initiatives stems from employers redefining employees as independent contractors to avoid labour legislation. The Labour Relations Act (1995) and Basic Conditions of Employment Act exclude independent contractors from the definition of employee. This form of labour market flexibility is often aimed at gaining exemption from basic labour standards and circumventing statutory obligations, through downward variation of basic conditions. This may be done by agreement or ministerial exemption (Creamer, 1997). It externalises the employment relationship, altering it to a commercial relationship of letting and hiring services.

Although there is some consensus on reasons for implementing owner-driver schemes, little empirical research has occurred. This article reports an exploratory investigation into the reasons for owner-driver schemes and experiences of companies and owner-drivers in implementing them. The article provides an understanding of the current status of ownerdriver schemes. The focus is on schemes in the Western Cape. Our research objectives are to: identify reasons why companies restructure their workforce to include owner-driver schemes, perceptions of owner-drivers towards such schemes, implementation methods, and advantages and disadvantages of owner-driver schemes.

\section{Impact of owner-driver schemes on productivity}

This section deals with a review of relevant international literature on the topic.

An owner-driver is a self-employed driver who undertakes delivery of product, using his own vehicle, on behalf of a larger organisation that, typically, was his former employer. Owner-driver schemes concern the contracting out of an organisation's distribution services, to improve productivity and flexibility. While some companies employ owner-drivers who are independent of the company, most develop owner-driver schemes from within existing and/or former employees. Owner-drivers, irrespective of the business-format (e.g. sole trader, close corporation) adopted, are viewed as independent distributors, often tied into exclusive contracts with the 'parent' company. Distribution of product is a service provided for the benefit of customers purchasing that product. Quinn \& Paquette (1990) argue that external service groups can provide greater economies of scale, flexibility, and levels of expertise for specialised overhead services. By implication, companies that outsource activities not part of their core competencies may be able to leverage their resources for competitive advantage. Either low or high skill work may be outsourced for different reasons; the latter occurring when a 
firm seeks specialised skills (e.g. certain types of training) it does not have or an important activity it is weak at. Most common motivations for outsourcing include cost and risk reduction, and focus on core competencies and value-added skills (Lever, 1997).

Individual empowerment and stimulating economic activity are also motivating factors. Employee empowerment is a strategy by which decision-making power is passed on to employees in order to bring it closer to the customer contact point (Gopal \& Cypress, 1993: 226). This gives a job greater depth and its incumbent more responsibility. Effective empowerment programmes can enhance work motivation and identification with the enterprise. These four factors may complement each other, though externalising and commercialising the employment relationship may have an adverse impact on direct or standard employment and tends to reduce labour standards.

As with quality improvement, time-based competition has become popular (Stalk, 1988). Tomasko (1993: 57-58) refers to three areas of potential improvement by minimizing cycle times: product development process; customer order process; and problem resolution process. Customers with expectations set by the best companies across industries, demand higher quality at lower cost, rapid response, and immediate availability at the time of procurement and usage. Suppliers are increasingly being evaluated, not only on the basis of process capability and quality but also on the basis of ability to deliver just-in-time in small lots and at greater frequencies to point of use (Gopal et al., 1993: 5).

Quinn \& Hilmer (1994: 43) refer to two strategic approaches that, when properly combined, allow managers to leverage their company's skills and resources competitively: firstly concentrating the firm's own resource on a set of 'core competencies' where it can achieve definable pre-eminence and provide unique value for customers. Secondly, strategically outsourcing other activities - including some traditionally considered integral to a company - for which the firm has neither a critical strategic need nor special capabilities.

Quinn et al. (1994: 44-47) note there is little theory or consistency about core competency. The concept of core requires that managers think much more carefully about which of the firm's activities potentially create unique value and which activities managers could more effectively buy externally. They suggest that effective core competencies are: skill or knowledge sets, not products or functions; flexible, long-term platforms - capable of adaptation or evolution; limited in number; unique sources of leverage in the value chain; areas where the company can dominate; elements important to customers in the long run and elements embedded in an organisation's systems. Similarly, Spalding (1997: 28) argues that a firm can, by outsourcing, lose control over an important business process. If it is function strategic to an organisation's competitive edge, this could be a very high risk. Outsourcing can entail upheaval, transfer of significant assets, dislocation of people and long-term contractual obligations. The benefits and risks have to be clearly understood and managed. Training investment may be lost through layoffs or resignations of skilled employees. This will reduce incentive to invest in training with firms giving priority to skills when recruiting, rather than considering potential and aptitude (Bassi $e f$ al., 1997: 18-19).

An increasing number of companies are outsourcing functions traditionally performed in-house. Gopal et al. (1993: 200) regard outsourcing as particularly useful in three situations: firstly, where an organisation requires specialised skills that it does not wish to invest in or that lie outside its core competencies; secondly, where an organisation decides to focus on core competencies in terms of management resources and investment; and lastly, where an outside supplier or resource is able to deliver product and service quicker and more reliably at less cost or at consistently better quality than can be done internally. Owner-driver schemes involve outsourcing distribution. The first of these situations would be least applicable. The third point implies that outsourcing need not always refer to the outsourcing of non-core activities. The unlikely outsourcing of a core activity is not excluded. Quinn et al. (1994: 52) conclude that most western companies use outsourcing primarily to save on overhead or short-term costs; the result being a piecemeal approach. This often results in patches of over-capacity scattered at random throughout company operations and large numbers of subcontractors that are more costly to manage than in-house operations that are individually less efficient. By contrast, Japanese companies outsource primarily to improve efficiency and quality of their own processes, focus on few sources, build inter-dependent relationships, and hold on tightly to high value-added activities crucial to quality. The nature of contractual arrangements between companies and their owner-drivers reflects this inter-dependent relationship.

Lacity, Wilcocks \& Feeny (1995: 84) refer to outsourcing on the basis of whether an operation is a core strategic service or a commodity that does not differentiate a company from its competitors. This is based on an assumption that managers can predict with some certainty the future of their markets, new technologies and suppliers' capabilities and motives. This is not feasible in a turbulent, unpredictable and complex world, requiring flexibility of response. The rationale for flexibility is economic in origin: to compete in world markets and react swiftly to changing consumer demand whilst reducing unit labour costs (Prowse, 1990). The issues of control and flexibility are echoed in the work of Quinn et al. (1994). However, when the potential for both competitive advantage and strategic vulnerability are high, the company may need a high degree of control, usually entailing production internally through joint ownership arrangements or tight long-term contracts. The opposite occurs where little competitive edge is possible and there is an active and deep market of supplier firms. In between, there is a continuous range of activities requiring different degrees of control and strategic flexibility. There is often a trade-off between flexibility and control.

An important purpose of outsourcing is to have the supplier assume certain investments and risks, such as demand variability. There is a full spectrum of outsourcing arrangements dependent on a company's needs - the issue is less whether to make or buy an activity than how to structure internal versus external sourcing on an optimal basis. In terms of the above frameworks owner-driver schemes would typically occupy a position where moderate control is required that can be fulfil- 
led by some sort of mid- to long-term contractual arrangement.

\section{Owner-driver schemes and flexibility in South Africa}

In addition to resource and operations flexibility required to meet unpredictable customer demand, organisations are increasingly using employment flexibility. Horwitz \& Franklin (1996: 4-6) refer to Sullivan's definition of employment flexibility as 'the ability of an organisation to respond to product and labour market pressures on demand and supply sides and changes in employment conditions'. Flexibility initiatives can include flexible scheduling, referring to flexible work schedules, job-sharing, telecommuting, new shift systems, satellite offices, shared offices, factory process reorganisation; and flexible staffing. The latter refers to temporary hiring, part-timers, independent contractors and internal temporary pool employees - people that are recruited into an 'on-call' pool that the company manages (Thomburg, 1994: 46-48). Factors driving workplace flexibility in SA are not substantially different from those elsewhere - these include restructuring and changing labour market patterns, and declining employment in traditional industries.

Thomburg (1994: 46) refers to factors motivating companies to search for workplace flexibility. These include external and internal pressures or a combination of both - which may lead to organisational change. The former include competition for highly trained employees who demand flexibility, changes in workforce demographics, and customer expectations. Internal pressures include the costs of low productivity, absenteeism, work-to-rule tactics, and turnover (Hall \& Parker, 1993: 9). While a combination of both internal and external pressures apply, important factors regarding ownerdriver schemes are timeous delivery, transportation and service quality.

Employer benefits of flexible work practices, including productivity improvements, have been documented internationally and in SA (Hall et al., 1990: 6; Horwitz, 1995; Horwitz \& Franklin, 1996; and Thornburg, 1994: 46). This research shows that effective flexible work practices are included in business planning at enterprise level. The Labour Relations Act (1995) requires consultation with a view to reaching consensus with trade unions on the design and implementation of flexible work practices. The Transport and General Workers Union (TGWU) recently negotiated a National Bargaining Council for the goods transport industry (Forrest, 1997: 25). Owner-drivers, though self-employed, may be represented by a trade union in negotiations on owner-driver schemes. The outplacement of employees as with owner-drivers is a particular form of workplace flexibility. However, unlike retrenchment, bonds between the company and its former employees are not severed. The above requirements are important in a successful start-up of ownerdriver schemes. The preceding discussion on flexibility has focused on employer motives. However, satisfying employee needs can boost productivity. It is equally important to view flexibility in respect of employment security, job satisfaction and motivation (Hall et al., 1993: 15; Horwitz \& Frost, 1992: 30). Individual empowerment and actualisation of ownerdrivers are important. Customers are immediately and di- rectly affected by service delivery mistakes and employees' willingness to correct them (Bowen \& Lawler, 1995: 74).

Owner-driver schemes are a specific form of employee ownership that needs careful planning and implementation if an organisation is to benefit. While the creation of independent satellite businesses such as owner-driver schemes do not necessarily fall within the conventional sense of employee ownership, there are precedents for this type of empowerment (Semler, 1994: 66). This supports government policy to promote small and medium-sized businesses by the development of closer business linkages between small and large businesses. Where possible, big business will be encouraged to outsource and subcontract orders to the smaller players (Reconstruction \& Development Programme, 1994: 33).

There are interdependent factors relating to outsourcing and productivity improvement. Factors that complement each other are those which have a more direct impact on employ. ees, namely the promotion of entrepreneurial endeavour, employee empowerment and flexible work practices. Each of these are directly focused on providing, to some extent, employees with rewards commensurate with their contributions to the organisation. Increased specialisation that may result from focusing on core competencies also has a direct impact on employees; but in this instance the strategy is organisationally focused. Focusing on core competencies, however, could relegate those employees involved in non-core activities to a second-class status. A negative impact of outsourcing is the retrenchment process that often accompanies it, for both retrenchees and 'survivors'. An organisational culture in the aftermath of retrenchment is often characterised by low morale and insecurity (Moses, 1994: 50). In this regard, owner-driver schemes are a more creative option to outsourcing than a complete severance resulting from retrenchment.

It can be problematic to outsource distribution where it is a core organisational competency. Companies whose business is the provision of a distribution service on the behalf of others, for example courier companies, cannot argue that distribution is non-core. Outsourcing is useful if the outside supplier is able to deliver products quicker and for less than can be done internally. This would imply a seemingly contradictory, although logically correct, approach to focusing on core competencies in the case of a distribution company that decides that improving its core competency is best achieved by outsourcing it.

\section{Research methodology}

There is limited research on the design and implementation of owner-driver employment or sub-contracting schemes. A semi-structured questionnaire was designed as the basis for interviewing spokespeople for companies implementing owner-driver schemes, and owner-drivers themselves. Both organisations as well as owner-drivers were interviewed. Questions focused on organisation policy, motivations and practice. As contact with owner-drivers was made with the assistance of core organisations it can be argued that their answers may be biased in terms of the halo affect. Efforts were made to assure owner-drivers that their answers would remain confidential. The research instrument was validated by pre-testing and piloting (Straub, 1989). An initial validation was conducted by discussing the questionnaire with 
human resources consultants with experience in the implementation of owner-driver schemes. Modifications were made after which the questionnaire was piloted on later participants in the study. The final questionnaire was used as the basis for semi-structured interviews conducted with eight organisations in the Western Cape province using ownerdriver schemes and 25 owner-drivers themselves.

The literature survey concentrated on motivations to implement owner-driver schemes as a method by which to improve productivity in distribution. To this effect, the representative model of owner-driver schemes was developed. Although the research instrument seeks information beyond the immediate motivation to implement owner-driver schemes, it does not attempt to prove the model. However, it is possible to develop the following hypothesis based on the promotion of productivity improvement:

The implementation of an owner-driver scheme is an

effective method by which to increase productivity in

the distribution requirements of an organisation.

As this was an exploratory study, it was necessary to identify organisations that had implemented owner-driver schemes and/or which are currently involved in their implementation. This was done by using information provided by the business press and leads given by consultants involved in this area. Given the exploratory nature of this study the sample is a regional one. Information obtained is of a qualitative nature. Statistical analysis is limited to aggregated descriptive results from the interviews. In view of the relevance of this area to current business practice the results of this study ought to provide a good basis from which to identify areas for additional research.

\section{Results}

Eight companies were involved in the study. In each case, the spokesperson for the company was the distribution or transport manager who, in turn, identified the owner-drivers who were potential interviewees. The findings are presented according to categories used in the questionnaire (see Table 1).

\section{Motivating reasons}

The semi-structured approach to these questions does not allow for an analysis based on ranking of a number of factors. However, a number of common factors emerged. These and the number of companies which cited the factor as being important to the company, are presented in Table 2.

Replies to the length of time during which the scheme had operated ranged from eight years to one month, excluding those that had not started or were still in their first month of operation. Three of the companies had had the scheme for over four years.

Although these results do not allow for ranking or relative rating they do give a clear indication of which factors can be

\begin{tabular}{lcccccc}
\hline Table 1 & Industry sectors of participating companies \\
\hline $\begin{array}{l}\text { Industry } \\
\text { sector }\end{array}$ & $\begin{array}{c}\text { Food \& } \\
\text { beverages }\end{array}$ & Energy & Courier & $\begin{array}{c}\text { Engineer- } \\
\text { ing }\end{array}$ & $\begin{array}{l}\text { Pharma- } \\
\text { ceutical }\end{array}$ & Total \\
\hline $\begin{array}{l}\text { No. of } \\
\text { companies }\end{array}$ & 3 & 1 & 2 & 1 & 1 & 8 \\
\hline
\end{tabular}

Table 2 Motivation factors cited by participating companies

\begin{tabular}{lc}
\hline $\begin{array}{l}\text { Motivating } \\
\text { factor }\end{array}$ & $\begin{array}{c}\text { No of } \\
\text { companies }\end{array}$ \\
\hline Increase productivity & 8 \\
Improve customer service & 5 \\
Give owner-drivers a personal stake in the company, i.e. & 4 \\
empowerment & \\
Benefit from entrepreneurial endeavour stemming from & 4 \\
personal involvement and the profit motive & \\
Reduce company assets & 1 \\
Reduce distribution costs & 4 \\
Ensure long-term competitiveness & 1 \\
Create more jobs & 2 \\
Outsource non-core activity & 1 \\
Open new markets & 1 \\
Promote numerical workforce flexibility & 3 \\
Reduce trade union activity/involvement in the company & 2 \\
\hline
\end{tabular}

considered important. In isolating the factors referred to by half (four) or more companies, the following are identified: productivity improvement, improvements in customer service, empowerment of employees, entrepreneurial endeavour, and reduction of distribution costs. These results confirm that productivity improvement is an essential component of owner-driver schemes. While improvements in customer service and the reduction of distribution costs were not specifically given as motivating factors these are viewed as componerits of productivity improvement. Empowerment and the promotion of entrepreneurial endeavour feature strongly although the promotion of numerical workplace flexibility is mentioned by three of the organisations.

\section{Use of external consultants}

Three-quarters of companies had used outside consultants, mainly for expert help on the legal implications of the schemes. Consultants were involved in all aspects of the scheme, including the selection of owner-drivers and, often, as business consultants to the owner-drivers themselves. Several companies used others as sounding boards for discussing the implications of the schemes.

\section{Trade union involvement}

Horwitz \& Franklin (1996) and Standing \& Macum (1996: 812) refer to the importance of involving unions in decisions affecting employment flexibility. They provide evidence that work-place flexibility in SA is often negotiated with trade unions. All of the more recently implemented schemes investigated here, involved unions in discussions prior to scheme implementation. Trade unions are concerned with maintaining employment standards, security and worker rights. Unions have concerns about conditions of employment for truck crews. There appears to be a more pragmatic response from unions in contrast with oppositional tactics adopted in the introduction of some schemes in the late 1980s. Although most companies report 'stable' relations with unions applicable to distribution, two mentioned that 
reducing vulnerability to union activity was a motivating factor for introducing the scheme.

\section{Method bf implementation and support}

Several companies use pilot schemes to gauge long-term success of a scheme. This was considered essential to prove and refine the concept before wider implementation. Problems arise most commonly as a result of insufficient development of pilot schemes (Leshilo, 1995: 19). Most respondents retained their previous method of distribution except that the service provider was no longer an employee of the company. Only three owner-drivers distribute van-sold goods (drivers sell to their own accounts) as opposed to presold goods. Pre-selling of product, the conventional approach, involves taking a customer's order prior to the delivery of the product. Van-selling involves selling the goods on demand and on-site. Companies, with relatively large numbers of owner-drivers, rely solely on owner-drivers. Companies that have a smaller distribution workforce, owner-driver or otherwise, prefer a mix of internal employee and owner-drivers, to guarantee delivery. There are several areas related to business administration, financial assistance and planning, and vehicle maintenance where support is offered, in varying degrees, to owner-drivers. Some companies built in free financial administration and planning in the initial months after the scheme started in order to smooth the transition. An important area of support concerns assistance with obtaining loans from banks and the Small Business Development Corporation (SBDC) to finance vehicles. Initially, owner-drivers do not have a credit rating acceptable to many financial institutions. The type of support varies from standing guarantor to the negotiation of fleet discounts. This initial support was followed by an increase in credit-worthiness.

\section{Productivity and incentives}

All respondents report increased productivity. Work motivation is particularly relevant to the hypothesis developed. All owner-drivers interviewed stated unequivocally that they worked considerably 'harder' than before. However, there are instances where some owner-drivers have not fully accustomed themselves to not being employees and do not put in as much extra work as is expected by the incentives concerned.

Most (six) companies preceded the implementation of schemes by a careful analysis of routes used and distribution history to ascertain a 'break-even' level which was realistic and achievable. All schemes were incentivized. Income was dependent on the number of deliveries accomplished or sales made. However, this was not always a simple rand per case payment system owing to the existence of factors largely beyond the control of the owner-driver, such as drop size, vehicle size, type of customer, and off-loading times. Different methods of determining the level of productivity were used. Payment based on the performance of an owner-driver against standards in areas such as driving time, off-loading time, depot time, fuel usage, and vehicle maintenance, is one method. These standards are set so that a competent driver should be able to achieve them on a normal basis whereas a motivated driver would be able to exceed the standards and earn additional money. Standards are based on a realistic productivity improvement over in-house driver performance thereby resulting in cost-savings for the company. Incentivization was more easily accomplished in cases of bigger com. panies who had regular clients - it is relatively simple to build up a productivity profile based on a history of previous deliv. eries. Companies, such as courier services, service a much wider distribution of clients many of whom do not receive products often or take delivery at irregular intervals - a lack of distribution history and the necessity to alter daily routes to accommodate deliveries in the most efficient possible manner exclude the possibility of basing remuneration on distribution times specific to particular clients.

\section{Advantages and disadvantages of the scheme to the company}

Many of the advantages echo the motivational factors previously discussed. Some of the disadvantages listed below apply more directly from the perspective of the owner-driver but can have repercussions for the company. Advantages include: improved customer service - as reported by com. pany records and, in one case, by independent market research; reduced distribution costs; reduced union involvement (though potentially controversial); opportunity to introduce further incentive schemes; and with maturation of the scheme, annual rate negotiations have become more realistic as owner-drivers have developed an understanding of economic issues.

Disadvantages include: receiver of revenue problems in early stages owing to drivers failing to register correctly with the taxation authorities; mismanagement of funds by ownerdrivers, especially as regards making provision for vehicle repairs and/or replacement; difficult to introduce because people resist change; could be construed as an unfair labour practice; moral obligation to use drivers even where a cheaper distribution method becomes available. Should owner-drivers exploit their employees, detrimental effects may result in reduced productivity. The public image of the company may be adversely affected. Most (six) companies argued that advantages outweighed the disadvantages. A thorough analysis of a scheme is necessary prior to its introduction, by ensuring contractual safeguards to reduce the risk of problems, and by ensuring that the scheme is carefully managed.

\section{Exclusive service versus surplus capacity}

The ability to use surplus capacity elsewhere, is related to the nature of the vehicle, for example in the case of the company that passes on ownership of the truck-tractor but retains ownership of the trailer, the owner-driver would only be able to use surplus capacity if he were to have his own trailer. Apart from the above example a third of the companies tie their owner-drivers into exclusive contracts although some of the others prevent surplus capacity being used for competitor products. Most owner-drivers, after having met their contractually required company deliveries, are free to use their vehicles for other delivery work. There is a difference between owner-driver schemes and traditional franchising as most franchise agreements tie the franchisee into an exclusive contract. Although it can be argued that employee exploitation will adversely affect owner-driver income and, as a result, incorporates a self-correcting mechanism, such a mechanism is unlikely to kick in soon enough to prevent an 
adverse impact on customer service and profitability. It is preferable to provide agreements with sound labour relations provisions.

\section{Vehicle ownership}

The term 'owner-driver' implies that ownership of the distribution vehicle passes on to the driver. Different companies use different methods of passing on ownership. While some companies, particularly those that use larger delivery vehicles, transfer ownership only after an initial phasing-in period, five years in one case, most companies transferred ownership immediately. In such cases, the company assisted the drivers to obtain the necessary finance from an appropriate financial institution. A company may retain ownership of trailers partly to maintain standards required by the company as regards corporate image and reliability. Half of the respondents have owner-drivers who possess more than one vehicle. None of the companies prevented or discouraged multiple vehicle ownership of owner-drivers. Owning more than one vehicle depends largely on the initiative and entrepreneurial ability of the owner-driver. Ownership per se does not automatically produce the benefits required to improve organisational performance - ownership schemes must be carefully designed and managed.

\section{Recruitment and selection criteria}

Three-quarters of companies recruited owner-drivers internally. A third looked both externally and internally for ownerdrivers. Differences in recruitment processes concern the vetting process. Different levels of vetting are applied in determining the suitability of a driver to become an ownerdriver. The most stringent vetting consisted of: considering previous driving record, history of providing customer service; assessment, using psychological tests and interviewing, of the driver's ability to successfully manage as an independent businessman, using the following criteria: customer orientation, entrepreneurial flair, technical ability, fairness in employment of others, honesty, financial and legal ability. Some respondents used their potential entrepreneurial ability as one of the criteria to vet suitability. The use of a tried and tested vetting system is similar to using a pilot implementation scheme. It provides a method of reducing potential problems that may surface later.

\section{Advantages and disadvantages to owner-drivers}

As with the spokespeople for the companies interviewed, a number of owner-drivers expressed similar advantages and disadvantages. Advantages included: better income, more interesting work - wider knowledge required of distribution and business in general, better opportunities to expand horizons, and owning an asset. Having one's own business raises the individual's status when needing to approach financial institutions for assistance. Disadvantages included: management of employee problems and less time for oneself and family. Workers in sub-contracting firms may be paid less than standard or core workers, have insecure employment, minimal access to fringe benefits, are unlikely to remain with a particular firm for any significant time and are poorly unionised (Camoy, Castells \& Benner, 1997: 30).

\section{Conclusions}

If one regards the motivating reasons previously discussed, as providing sufficient evidence that companies require increased productivity in their distribution requirements, the advantages given by companies and owner-drivers need to be assessed in terms of the contribution they make towards improving productivity. The dominant impression is that owner-driver schemes result in harder working drivers who lower distribution costs and improve customer service, that is, distribution becomes more productive. The findings provide qualitative support for the hypothesis. Important in this regard are these motivating factors: entrepreneurship, core competencies, empowerment and workplace flexibility. The following were important to over half of the interviewed companies: productivity improvement, improvements in customer service, empowerment of employees, entrepreneurial endeavour, and reduction of distribution costs.

Two of the motivating factors, namely empowerment and entrepreneurship, appear to be most commonly mentioned as motivating the drive towards owner-driver schemes. The validity of these factors needs to be assessed in terms of the extent to which factors are independent of each other; considering whether some factors should be omitted or replaced by others; and the extent to which factors interact with each other. This exploratory study of motivational factors of owner-driver schemes, implementation and various issues that affect these schemes, analysed the experiences of a number of companies, primarily based in the Western Cape. The findings present a foundation comprising issues affecting the design, implementation and management of owner-driver schemes. This base information is available for more quantitative research and for determining additional areas of research. The specific findings on productivity improvements and reasons for adopting these schemes contribute towards an assessment of the hypothesis developed in our article. Three types of further research are suggested: firstly, using the same research instrument but adapting the questions so that, where applicable, answers can be ranked and/or rated, that is a more quantitative approach; secondly, amending the research instrument to focus on specific issues, that is restrict the research scope, while enhancing the depth of analysis; and thirdly, focusing on areas omitted by this research instrument in conjunction with or in isolation from areas already covered.

The following should receive attention: distinguishing characteristics of successful owner-drivers; an assessment of their entrepreneurial characteristics; incentive methods and remuneration structures; level of competition between ownerdrivers, quantitative, financial measures of success, union involvement, perceptions of owner-driver crew members, failed schemes, methods by which to promote continuous improvement in owner-driver productivity, and proving the representational model.

As with the current research, the suggested areas of additional research would benefit by using a more representative sample. Also, since this is an exploratory study using interviewees who are largely satisfied with their owner-drive schemes, the importance of the idea would be highlighted by: 
- conducting a survey of a representative sample across other business sectors where distribution is important, to determine to what degree owner-drivers schemes are being used;

- determining the degree to which owner-driver schemes are being considered by organisations without such schemes at present.

While the nature of the research instrument and the scope of the study limit the degree to which it is possible to draw generalisations, some important issues emerge. The goal of increasing productivity is the objective of most companies following this route; a number of motivating factors emerge as driving towards this goal. Perceptions of owner-drivers were largely used to analyse various aspects of the ownerdriver system from the perspective of the company. All of the owner-drivers interviewed expressed a positive opinion on the owner-driver schemes. Two main owner-driver distribution methods emerge, namely pre-selling and van-selling, although one scheme also involved the installation, on the client's premises, of the product sold. The use of pilot implementation schemes is important in ensuring long-term success of the scheme. A number of advantages and disadvantages are given by both the companies and the owner-drivers. Potential disadvantages include limited access to fringe benefits and fair labour practices, deterioration in pay and employment security, this especially so for crew members. Collective labour rights may thus be undermined.

Mindful of the importance of maintaining minimum employment standards and basic worker rights, as referred to in the Labour Relations Act (1995) and the Basic Conditions of Employment Act (1997), it appears that owner-driver schemes can be an effective mechanism by which to increase productivity. They also give employees the opportunity to be rewarded financially and in terms of job satisfaction, in direct relation to work effort. Owner-driver schemes

'are becoming necessary to ensure long-term competitiveness. Franchising, joint ventures, sub-contracting and other empowerment mechanisms are increasingly being debated in boardrooms' (Leshilo, 1995: 19).

\section{References}

Bassi, L., Cappelli, P., Katz, H., Knoke, D., Osterman, P. \& Useem, M. 1997. Assessing the effect: outcomes of restructuring. Change at work, National Policy Association: 18-19.

Bowen, D.E. \& Lawler, E.E. 1995. Empowering service employees, Sloan Management Review, 36(4): 73-84.

Creamer, K. 1997. Side-stepping and ducking employers under fire, Sunday Business Times, August 28: 1.

Gopal, C. \& Cypress, H. 1993. Integrated distribution management: competing on customer service, time and cost. New York: Irwin Professional Publishing, 5: 200-226.

Forrest, K. 1997. Lightening the load, South African Labour Bulleting, 21(1): 25-26.

Hall, D.T. \& Parker, V.A. 1993. The role of workplace flexibility in managing diversity, Organisational Dynamics, 22(1): 4-18.

Horwitz, F.M. \& Frost, P. 1992. Flexible rewards: critical success factors, People Dynamics, 10(9): 27-33.

Horwitz, F.M. 1995. Flexible work practices in South Africa: economic, labour relations and regulatory considerations, Industrial Relations Journal, 26(4): 258-266.
Horwitz, F. M. \& Franklin, E. 1996. Labour market flexibility in South Africa: research recent developments, South African Journal of Labour Relations, 20(1): 1-30.

Lacity, M.C., Willcocks, L.P. \& Feeny, D.F. 1995. IT outsourcing: maximize flexibility and control, Harvard Business Review, October: 84-93.

Leshilo, T. 1995. Owner-driver schemes now well on the road. Business Report - Cape Times: 19

Lever, S. 1997. An analysis of managerial motivations behind outsourcing practices, Human Resource Planning, 20(2): 39-40

Moses, M. 1994. Comparing retrenchment and renewal, HRM Yearbook, 9(10): 50-51.

Nasser, M. E. \& Vivier, F.J. 1993. Mindset for the new generation organisation. Kenwyn: Juta \& Co Ltd: 156.

Pierce, J.L., Furo, C.A. 1990. Employee ownership: implications to management, Organisational Dynamics, 18(3): 32-45.

Prowse, P. 1990. Assessing the flexible firm, Personnel Review, 19(6): 3-8.

Quinn, J.B., Doorley, T.L. \& Paquette, P.C. 1990. Technology in services: rethinking strategic focus, Sloan Management Review, 31(4): 67-78.

Quinn, J.B. \& Hilmer, F.G. 1994. Strategic outsourcing, Sloan Management Review, 35(4): 43-55.

Ryan, C. 1995. Productivity: the what and the how, People Dynamics, 13(2): 12-15.

SA Breweries Driver Entrepreneurship Scheme. 1989. Case study for class discussion. Cape Town: Graduate School of Business, University of Cape Town

SBDC. 1994: Small and medium enterprise development and job creating growth, Courier, 10(2).

Semler, R. 1994. Why my former employees still work for me, Harvard Business Review, October: 64-74.

Smit, P.J., \& Cronje, de J. 1992. Management principles. Kenwyn: Juta \& Co, Ltd: 181-182.

Spalding, A. 1997. Taking care with whom you dance, Sunday Business Times supplement on outsourcing. June 29: 28.

Stalk, G. 1988. Time - the next source of competitive advantage, Harvard Business Review, December: 41-53.

Standing, G. \& Macun, 1. 1996. Labour market dynamics in industrial enterprises: an overview of the 1995 South African Labour Flexibility Survey (SALFS), May: 1-11.

Straub, D.W. 1989. Validating instruments in MIS research, MIS Quarterly, 13(2): 147-170.

The Reconstruction and Development Programme: A Policy Framework 1994. The African National Congress, Johannesburg Umanyano Publications: 33.

Thornburg, L. 1994. Change comes slowly, HR Magazine, 39(2): 46-49.

Tomasko, R.M. 1993. Rethinking the corporation. New York: American Management Association: 2-6, 57-58.

\section{Appendix 1: Survey instrument}

The following questions form the basis of a semi-structured interview. Questioning did not necessarily follow the sequence indicated below:

\section{Company details}

- What industry sector?

- Are your competitors using such schemes? 
Scheme details

- What are the motivating reasons for implementing these schemes?

- How long has it been implemented?

- Were outside consultants used to help define and implement the scheme?

- Was there union involvement in scheme implementation?

- Was a pilot scheme used first?

- Describe the method of implementation, for example preselling versus van-selling

- Do internal drivers still exist? Why?

- What type/level of support (training, admin, repairs, etc.) offered by company to owner-drivers?

- How were remuneration levels determined?

- Any comments from clients?

- Advantages and disadvantages?

- Has productivity improved?

- Do any of your competitors have such schemes?

\section{Scheme contract details}

- Length of contract; renewed how often?

- Used exclusively for company work or can surplus capacity be used elsewhere?

- Are penalty clauses used?

- Are there any safeguards for truck crews?

Vehicle details

- Does ownership of vehicle pass to owner-driver?

- Are vehicles anonymous or do they carry a company logo?

- Do some owner-drivers own more than one vehicle?

\section{Owner-driver details}

- Recruited internally or extemally?

- How were they selected?

- Do they operate as sole traders, CCs, etc?

- Advantages and disadvantages

- Do you work harder? 